Supporting Information

\title{
Hydroxypropyl Cellulose Films Filled with Halloysite Nanotubes/Wax hybrid microspheres
}

Lorenzo Lisuzzo ${ }^{\mathrm{a}}$, Maria Rita Caruso ${ }^{\mathrm{a}, \mathrm{b}}$, Giuseppe Cavallaro ${ }^{\mathrm{a}, \mathrm{b}}$, Stefana Milioto $^{\mathrm{a}, \mathrm{b}}$, Giuseppe Lazzara $^{\mathrm{a}, \mathrm{b}^{*}}$

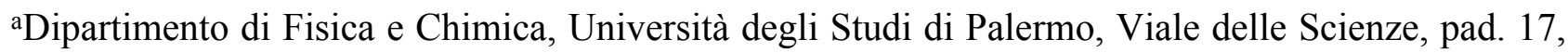
90128 Palermo, Italy.giuseppe.lazzara@unipa.it*

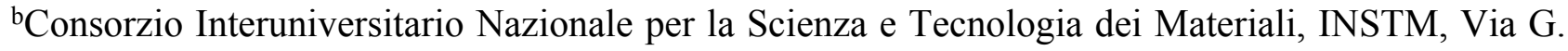
Giusti, 9, I-50121 Firenze, Italy

\section{Composite films thickness}

Table S1. Average thickness of composite films as a function of HNT:HPC mass ratio.

\begin{tabular}{|c|c|}
\hline Sample & Thickness (mm) \\
\hline $\mathbf{R}_{\text {Pick:HPC }}=0$ & 0.104 \\
\hline $\mathbf{R}_{\text {Pick:HPC }}=0.125$ & 0.136 \\
\hline $\mathbf{R}_{\text {Pick:HPC }}=0.165$ & 0.093 \\
\hline $\mathbf{R}_{\text {Pick:HPC }}=0.50$ & 0.096 \\
\hline $\mathbf{R}_{\text {Pick:HPC }}=0.75$ & 0.069 \\
\hline $\mathbf{R}_{\text {Pick:HPC }}=1.50$ & 0.083 \\
\hline
\end{tabular}

Sliding Angle setup.

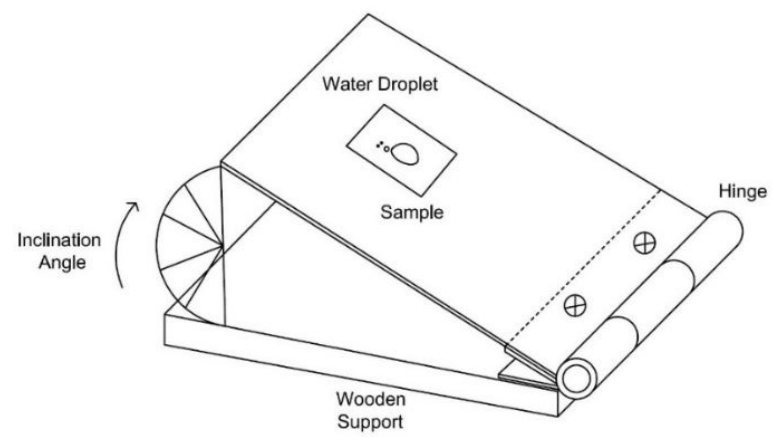

Figure S1. Representation of the sliding angle measurement setup. 
Water permeability analysis setup.

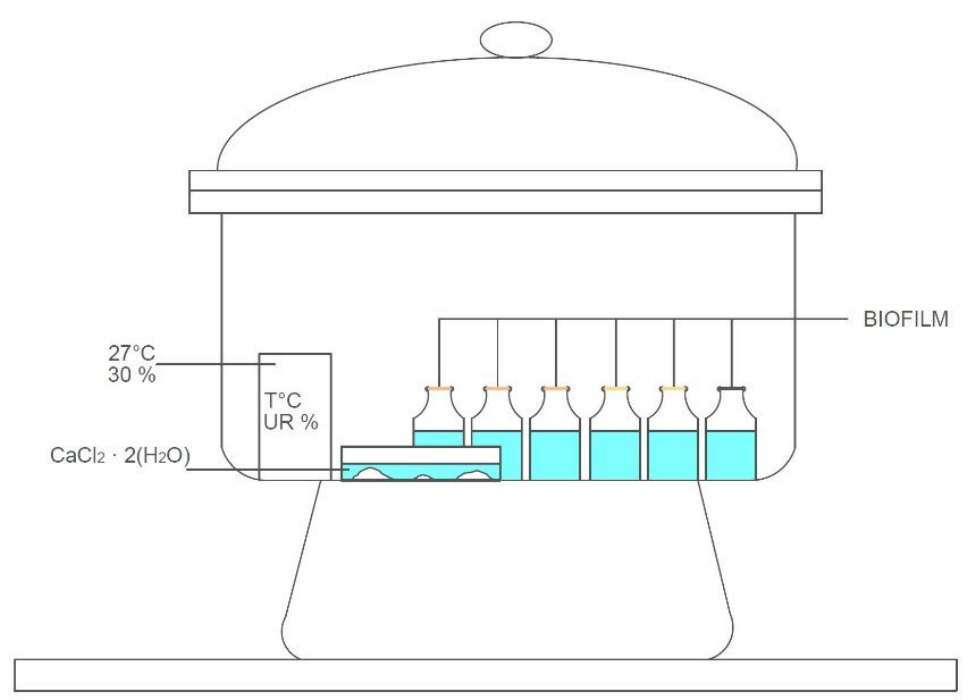

Figure S2. Drawing of desiccator for water permeability analysis.
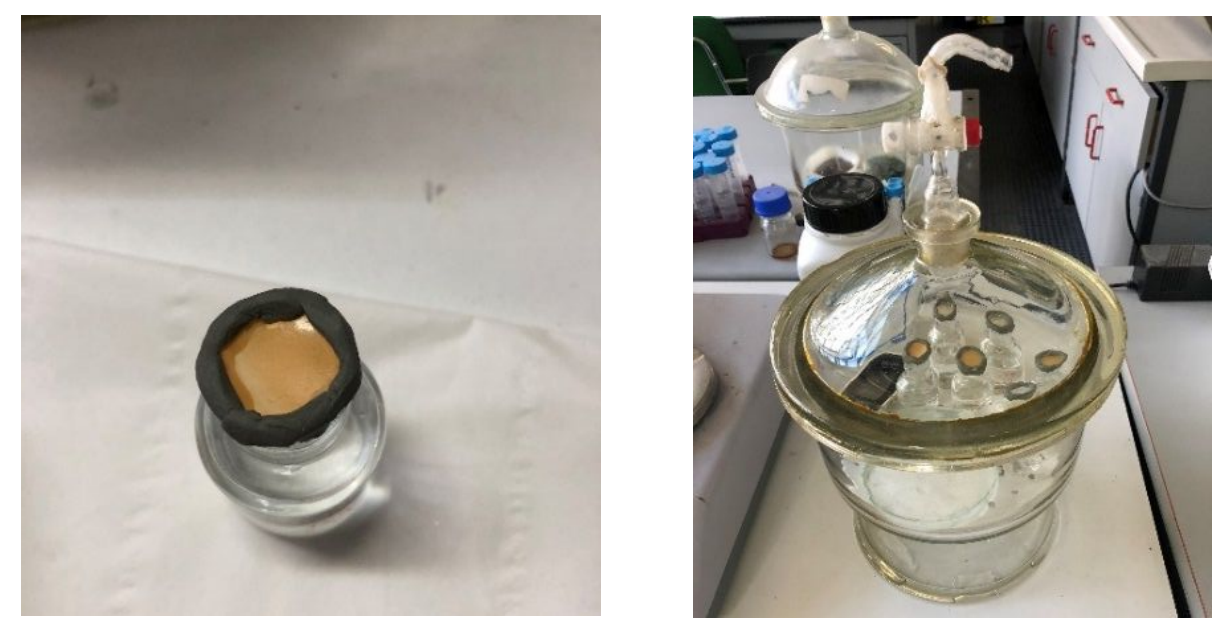

Figure S3. Bottle sample (left) and desiccator prepared for the water permeability experiments (right).

\section{Calculation from thermogravimetric data by rule of mixtures.}

Degraded matters at $700^{\circ} \mathrm{C}$ was estimated by using the equation:

$\mathrm{MD}_{700}=100-\left(\mathrm{MR}_{700}+\mathrm{ML}_{150}\right)$,

where $\mathrm{MR}_{700}$ is the residual matter at $700{ }^{\circ} \mathrm{C}$, while $\mathrm{ML}_{150}$ is the mass loss, and namely water content of the investigated material, between 25 and $150{ }^{\circ} \mathrm{C}$. 
The weight fraction of wax in the wax/halloysite particles $\left(\mathrm{x}_{\mathrm{wax}}\right)$ was calculated as:

$\mathrm{x}_{\mathrm{wax}}=\left(\mathrm{MD}_{700 \mathrm{P}}-\mathrm{MD}_{700 \mathrm{HNT}}\right) /\left(\mathrm{MD}_{700 \mathrm{WAX}}-\mathrm{MD}_{700 \mathrm{HNT}}\right)$,

where $\mathrm{MD}_{700}$ is the degraded matters at $700^{\circ} \mathrm{C}$ of wax/halloysite particles $\left(\mathrm{MD}_{700 \mathrm{P}}\right)$, Halloysite Nanotubes $\left(\mathrm{MD}_{700 \mathrm{HNT}}\right)$ and paraffin wax $\left(\mathrm{MD}_{700 \mathrm{WAX}}\right)$, respectively.

\section{Light attenuation coefficients}

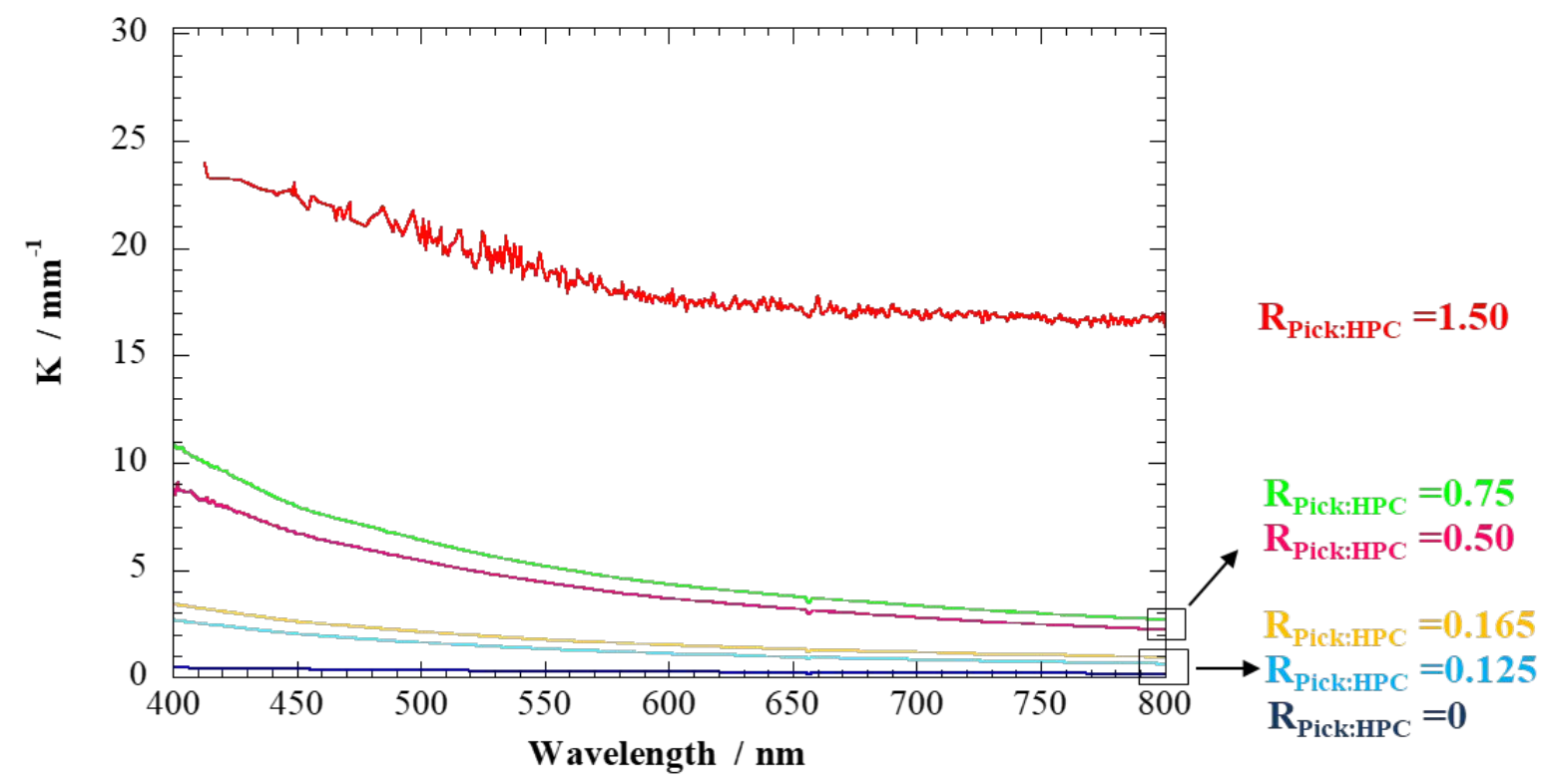

Figure S4. Light attenuation coefficients for all the investigated samples in the $400-800 \mathrm{~nm}$ wavelength range. 


\section{Thermal images}
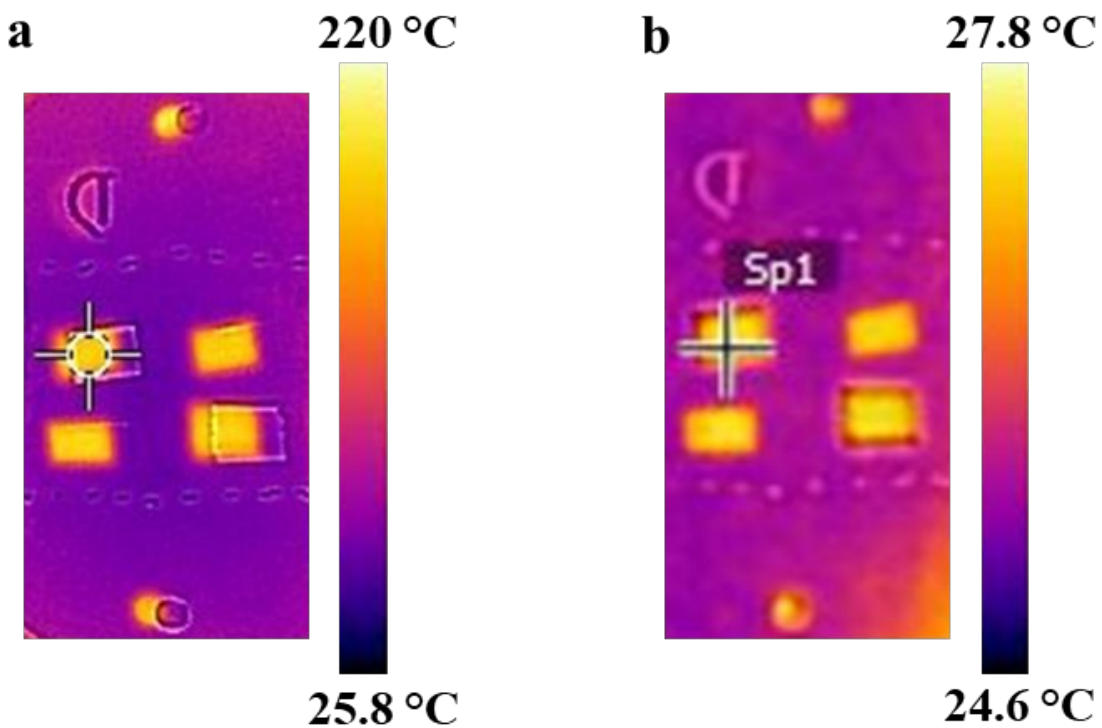

Figure S5. Thermal photographs of four composite films with an average area of ca. $1 \times 1 \mathrm{~cm}^{2}$. Images were taken after the maximum temperature of $170^{\circ} \mathrm{C}$ was reached (a) and at the end of the cooling process, which occurred at ca. $25^{\circ} \mathrm{C}(\mathrm{b})$. 